Original Article (short paper)

\title{
Acute effect of sodium bicarbonate supplementation on the performance during CrossFit ${ }^{\circledR}$ training
}

\author{
Luiz Paulo Toledo $^{1}$ (D) , João Guilherme Vieira² (D) , Marcelo Ricardo Dias ${ }^{1,3}$ (D) \\ ${ }^{1}$ Faculdade Metodista Granbery, Laboratório de Fisiologia do Exercício e Avaliação Morfofuncional, Juiz \\ de Fora, MG, Brasil; ${ }^{2}$ Universidade Federal de Juiz de Fora, Programa de Pós-graduação em \\ Educação Física, Juiz de Fora, MG, Brasil; ${ }^{3}$ CrossFit Juiz de Fora, Juiz de Fora, MG, Brasil. \\ Associate Editor: Ricardo Augusto Barbieri. Estácio UniSEB/Ribeirão Preto, SP, Brasil
}

\begin{abstract}
Aim: To verify the acute effect of sodium bicarbonate $\left(\mathrm{NaHCO}_{3}\right)$ supplementation on performance during CrossFit ${ }^{\circ}$ workout. Methods: Nine experienced males ( $30.8 \pm 3.5$ years; $84.4 \pm 9.5 \mathrm{~kg} ; 177.5 \pm 4.03 \mathrm{~cm} ; 2.2 \pm 1.0$ years) in CrossFit ${ }^{\circ}$ participated in this study. They were allocated to two conditions: a) supplementation with $0.3 \mathrm{~g}^{\mathrm{kg}} \mathrm{kg}^{-1} \mathrm{of} \mathrm{body}$ weight of $\mathrm{NaHCO}_{3}$ and b) supplementation with $0.045 \mathrm{~g} \cdot \mathrm{kg}^{-1}$ of body weight of sodium chloride $(\mathrm{NaCl})$. Blood lactate was analyzed at two different moments: before (lac-pre) and after the training protocol (lac-post). The heart rate (HR) and the rating of perceived exertion (RPE) were also collected every two minutes during the execution of the training protocol, and the RPE was also collected after it was finished. At the end of the training protocol, a questionnaire to measure gastrointestinal side effects (GSE) was answered by the participants. Repetitions performed in the training protocol was computed to evaluate the performance during the workout. Results: The results showed that there were no differences found when comparing the conditions for all parameters. HR and RPE were different in the first few minutes $(<4-6$ minutes) when compared to the final minutes ( $>14$ minutes) of the workout. The area under the curve of HR and RPE was significantly lower in the $\mathrm{NaHCO}_{3}$ condition. Conclusion: Acute $\mathrm{NaHCO}_{3}$ supplementation did not improve performance during workout 'Cindy' in experienced men. Supplementation also did not alter hemodynamic and perceptual parameters, nor did it cause any GSE. However, responses as a function of time were reduced with $\mathrm{NaHCO}_{3}$ supplementation.
\end{abstract}

Keywords: alkalosis; gastrointestinal tolerability; high-intensity functional training; muscle fatigue; performance-enhancing substances.

\section{Introduction}

Fatigue is one of the main factors that limit physical performance. Ways to decrease or delay fatigue have been extensively investigat$\mathrm{ed}^{1-3}$. High-intensity modalities cause an accumulation of lactate and hydrogen ions $\left(\mathrm{H}^{+}\right)$due to the predominance of the lactic glycolytic system, which results in limited amounts of oxygen for the functioning muscle cells ${ }^{4}$. Increased acidification of the intracellular environment has a direct influence on the development and perception of fatigue ${ }^{5}$.

Among the proposed mechanisms, related to cell acidification described in the literature, are the inhibitory effect on the activity of enzymes involved in glycolysis and glycogenolysis ${ }^{6}$, decreased calcium release and uptake by the reticulum sarcoplasmic ${ }^{7,8}$, reduced sensitivity of contractile proteins to calcium ${ }^{7}$, inhibition of crossbridge formation ${ }^{9}$ and increased ion efflux potassium ${ }^{10}$. However, our organism has intracellular (phosphate and dipeptide) and extracellular (bicarbonate - $\mathrm{HCO}_{3}^{-}$and plasma proteins) buffering mechanisms that help promote acid-base homeostasis ${ }^{11}$. The supplementation of sodium bicarbonate $\left(\mathrm{NaHCO}_{3}\right)$ increases the extracellular reserve of $\mathrm{HCO}_{3}{ }^{-}$which allows the formation of a positive electrochemical gradient of these ions out of the active muscle fibers ${ }^{12}$. The effects of $\mathrm{NaHCO}_{3}$ on sports performance have been investigated ${ }^{13-16}$. LopesSilva et al. ${ }^{13}$ showed that the $\mathrm{NaHCO}_{3}$ supplementation increases glycolytic contribution and improves performance during simulated taekwondo combat.

CrossFit ${ }^{\circledR}$ is a functional training program, constantly varied and with high intensity performed through metabolic conditioning, gymnastics movements, and weightlifting ${ }^{17}$. Despite the increasing popularity of CrossFit ${ }^{\circledR}$ training, there is still a lack of research, using supplements for performance optimization. Durkalec-Michalski et al. ${ }^{14}$ were the only authors to investigate the effect of $\mathrm{NaHCO}_{3}$ supplementation on a CrossFit ${ }^{2}$ workout and found that supplementation, in a chronic regime, when performed in progressive doses, improved performance in a specific workout ('Fight Gone Bad').

CrossFit ${ }^{\circledR}$ training provides several possibilities for performance purposes, hence the need for further clarification on $\mathrm{NaHCO}_{3}$ supplementation in different types of training such as shorter workouts (i.e. 'Fran' and 'Grace') and longer workouts (i.e. 'Cindy' and 'Murph') in order to optimize performance in the sport. However, there is a lack in the literature regarding the analysis of performance in CrossFit $\AA$ training when supplemented with $\mathrm{NaHCO}_{3}$. This study aimed to verify the acute effect of $\mathrm{NaHCO}_{3}$ supplementation on the performance during CrossFit ${ }^{\circledR}$ workout. We hypothesized that $\mathrm{NaHCO}_{3}$ supplementation would be effective in improving performance during

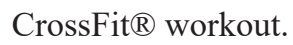




\section{Methods}

\section{Participants}

Nine male $(30.8 \pm 3.5$ years; $84.4 \pm 9.5 \mathrm{~kg} ; 177.56 \pm 4.03$ $\mathrm{cm} ; 26.7 \pm 2.2 \mathrm{~kg} / \mathrm{m}^{2}$ ) with experience in CrossFit $\AA$ training ( $2.2 \pm 1.0$ years of training experience), with minimum regularity of three uninterrupted months and a three-day weekly frequency, participated in this study. Before the study outset, the sample size was estimated using the G-Power package (version 3.1.9.2, Heinrich-Heine-Universitat in Dusseldorf, Germany $)^{18}$, considering an effect size $(\mathrm{f})=0.6$; power $(1-\beta)$ $=0.80 ; \alpha=0.05 ;$ correction among repetition measures $=0.5$ and nonsphericity correction $=1$ calculated by the procedures suggested by Beck ${ }^{19}$. Inclusion criteria for participation were: (a) to be regularly enrolled in a CrossFit ${ }^{\circledR}$ affiliate box; (b) to be normotensive and have no cardiovascular problems; (c) not using medicinal drugs or any ergogenic resources that could interfere with performance and (d) answering negatively to all questions in the Physical Activity Readiness Questionnaire (PAR-Q). After agreeing to participate in the research, all signed a consent form and were informed of all procedures in accordance with the Declaration of Helsinki (2000) and approved by the Research Ethics Committee of the Santa Casa de Misericórdia Hospital of Juiz de Fora (protocol number 024/2011).

\section{Experimental Design}

A counterbalanced double-blind crossover design was used in this study which happened over three visits. An Anthropometric evaluation was performed on the first visit to characterize the sample. That same day, participants were also familiarized with the research protocols. All were instructed to complete a food record from the last 24 hours before the first training session and repeat the same meals before the second training session. The experimental procedures then occurred over two days, in different consecutive weeks, with a seven-day washout period between them. Participants were randomly divided into two conditions, experimental $\left(\mathrm{NaHCO}_{3}\right)$ and placebo (sodium chloride - $\mathrm{NaCl}$ ).

In both conditions, blood samples were initially collected to measure blood lactate. Then, everyone performed a specific workout - 'Cindy'. HR and RPE were measured during training. Three minutes after the end of the training, another blood lactate collection was done $\mathrm{e}^{20}$, and the gastrointestinal side effects (GSE) questionnaire was answered by the participants. A global view of the experimental design is presented in figure 1.

To standardize, participants were instructed to (a) not drink alcohol during their entire participation in the study; (b) come to the laboratory two hours after their last meal in the morning; (c) not to consume drinks and foods that contain caffeine, and (d) do not practice vigorous exercise 24 hours before the workout.

\section{Anthropometric evaluation}

To characterize the sample, the height of the participants was measured using a wall stadiometer, with a measurement range from 0 to $220 \mathrm{~cm}$ and a graduation of $1 \mathrm{~mm}(\mathrm{Seca} \AA$, Seca 206 , Germany). Also, the total body mass was measured using a digital scale with a capacity of $150 \mathrm{~kg}(\mathrm{G}-\mathrm{TECH} \AA$, Glass $7 \mathrm{FW}$, China). All measurements were performed by a single evaluator responsible and experienced in the collection procedures. The body mass index was calculated using the following formula: body mass $/$ height $^{2}$.

\section{Supplementation Protocol}

The participants were subjected to two conditions with different supplements: experimental with $0.3 \mathrm{~g} \cdot \mathrm{kg}^{-1}$ of the body weight of $\mathrm{NaHCO}_{3}$ and placebo with $0.045 \mathrm{~g}^{\mathrm{kg}} \mathrm{kg}^{-1}$ of the body weight of $\mathrm{NaCl}$, that is, without any ergogenic effect ${ }^{16}$. The supplementation protocol used in both conditions was dissolved in $300 \mathrm{ml}$ of mineral water (Crystal $\AA$, Brazil) with a pH of 7.28 and a lemon-flavored juice $(\mathrm{Clight} \AA$, Brazil). This volume was divided into three doses of $100 \mathrm{ml}$, which were ingested with a 10-minute interval between them, totaling 30 minutes to complete the supplementation ${ }^{21}$. After ingesting all supplementation, participants waited for 60 minutes before the workout. The time for $\mathrm{NaHCO}_{3}$ absorption and dissociation to blood concentration occurs between 60 to 90 minutes after ingestion ${ }^{3,22}$.

\section{Training Protocol - 'Cindy'}

'Cindy' is a standardized CrossFit ${ }^{\circledR}$ workout, performed for 20 minutes AMRAP (as many repetitions as possible) ${ }^{17}$, with the combination of the following movements: 5 pull-ups, with the initial position hanging from the fixed bar, with elbows, extended, and the final position with the chin exceeding the bar; 10 push-ups, with body parallel to the ground and elbow extended, perform flexion of the elbows until the chest touches the floor; and 15 squats, in which the hip aligns with the knees and then a full extension. Initially, five minutes of joint mobility on the shoulders, hips, and ankles were performed. The number of repetitions performed in the workout was computed and a CrossFit $\AA$ coach was responsible for analyzing and validating the technique for each repetition. Concentric muscle failure was allowed to occur, in which participants performed a self-selected rest. All participants had prior orientation on the technique of executing each movement and verbal encouragement during the workout.

\section{Heart rate and Rating of Perceived Exertion}

HR and RPE were measured every two minutes during the workout, using an HR-monitor (Polar ${ }^{\circledR}$, FT 60, Finland) and the OMNI-RES scale ${ }^{23}$, respectively. The peak HR (HR-peak), average HR (HR-av), average RPE (RPE-av), and RPE five 
minutes post-workout (RPE-post5) was recorded. The maximum $\mathrm{HR}$ was calculated using the formula: $\mathrm{HR}_{\max }=220$ - age (years).

Regarding RPE, all the participants were oriented and familiarized with the scale, during one training session, and asked to determine the RPE as per the following instructions: (a) look at the illustrations and words to assist in the selection of a number from 0 to 10; (b) if you feel as shown in the illustration, that the effort is "extremely difficult", indicate number 10; (c) if they felt that the effort is between "extremely easy" and "extremely difficult", they should indicate a number between 0 and 10 , gradually, according to the illustrative descriptors present on the scale.

\section{Blood Lactate Assessment}

Blood lactate was collected before and after the workout. The blood sample was collected by a puncture in the distal phalanx of the index finger of the participants in aseptic conditions using a lancet (Roche ${ }^{\circledR}$, Accu-Chek Safe-T-Pro Uno, USA) and disposable gloves (Cremer ${ }^{\circledR}$, Brazil). After discarding the first drop of blood, $25 \mu \mathrm{L}$ of capillary blood was collected. For the determination of blood lactate, a portable lactate analyzer (Roche $\AA$, Accusport, USA) duly validated ${ }^{24}$ was used. Before testing, the lactate analyzer was calibrated with different standard solutions of known lactate concentrations $\left(2,4,8\right.$, and $\left.10 \mathrm{mmol} \cdot \mathrm{L}^{-1}\right)$.

\section{Gastrointestinal side effects}

The participants answered the GSE questionnaire after the workout. The questionnaire was validated to measure gastrointestinal discomfort ${ }^{25}$ and consists of a group of six items (nausea, stomach cramps, flatulence, belching, swelling, and diarrhea), describing common gastrointestinal symptoms. The numerical rating scale 0-10 (with zero reflecting no gastrointestinal discomfort and 10 indicating the most severe gastrointestinal discomfort) was used to classify the intensity of these symptoms ${ }^{26}$.

\section{Statistical analysis}

To calculate inferential statistics for the data, the normality of the distribution was assessed with the Shapiro-Wilk test, and the homoscedasticity with Levene's test. Blood lactate and HR were compared for the two conditions using a two-way analysis of variance (two-way ANOVA) with repeated measures (condition $\times$ time), followed by Bonferroni's post-hoc. The sphericality of the variables was tested using the Mauchly's test, in which we used Geisser-Greenhouse's epsilon ${ }^{b}$ to define the degrees of freedom. A paired t-test was used to compare performance through the maximum number of repetitions achieved in the workout, HR-av, HR-peak, and area under the curve (AUC) of HR between conditions. GSE, RPE-av, RPE-post5, and RPE-AUC were compared between the two conditions using Wilcoxon's nonparametric test. To compare the RPE during the workout, Friedman's non-parametric test was used. Pearson's correlation coefficients were calculated to analyze the relationship between body weight and performance in both conditions. The $R$-values of $0.1,0.3,0.5,0.7$ and 0.9 were considered small, moderate, large, very large and extremely large, respectively ${ }^{27}$. The $f^{2}$ Cohen's ES was calculated for the number of repetitions, HR-av, HR-peak, lactate, RPE-av, RPE-post5, and GSE to determine the magnitude of the differences. ES values of 0.2, 0.6, 1.2, 2.0, and 4.0 were considered small, moderate, large, very large, and extremely large, respectively ${ }^{27}$. The significance level was 0.01 and the software used for data analysis was SPSS Statistics for Windows, version 21.0 (SPSS Inc., Chicago, IL, USA) and GraphPad (Prism 8.0.1, San Diego, CA, USA).

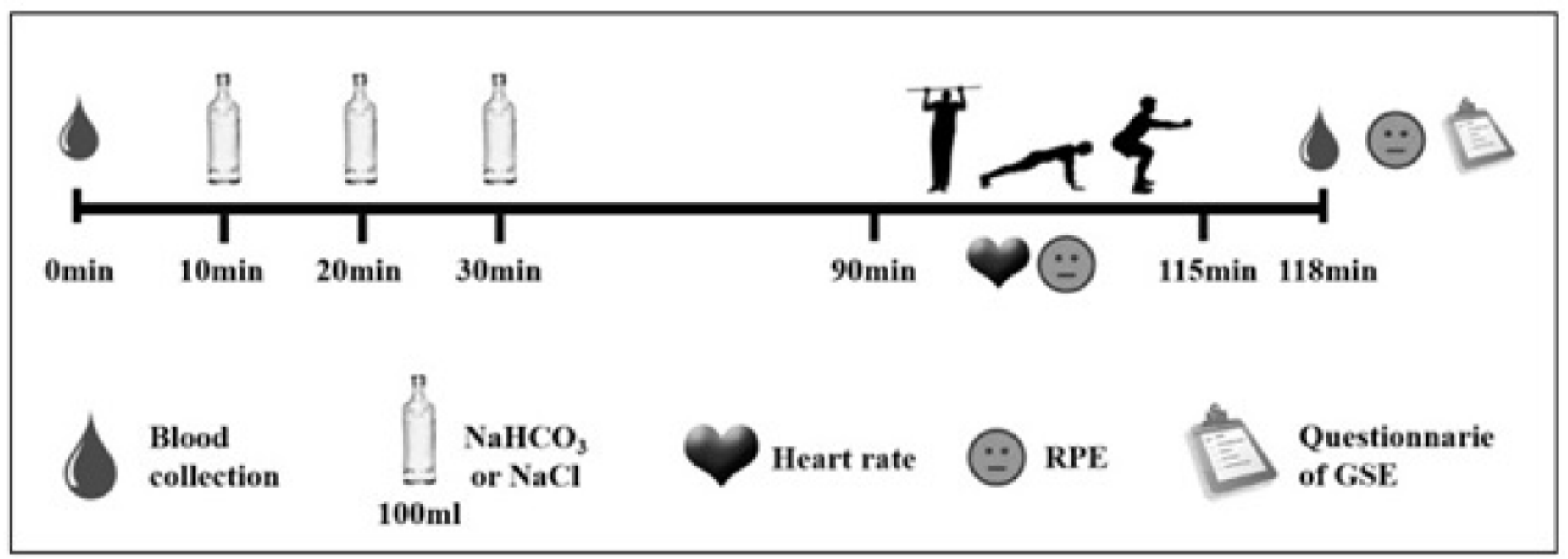

Figure 1 - Experimental design. 


\section{Results}

\section{Exercise Performance, Heart Rate, and Blood Lactate}

The paired t-test did not indicate a difference between $\mathrm{NaHCO}_{3}$ and placebo conditions for the maximum number of repetitions performed, HR-av, and HR-peak in the workout. Likewise, the twoway ANOVA with repeated measures showed that no significant interaction of lactate was found in relation to time $\times$ condition $[\mathrm{F}$ $(1,16)=0.80 ; p=0.384]$. In addition, there were no differences between the conditions $[\mathrm{F}(1,16)=1.6 ; p=0.227]$ for lactate-pre and lactate-post. The $f 2$ Cohen's ES was small for performance, HR-av, HR-peak, lactate-pre, and lactate-post (Table 1).

Neither relationship was observed between body weight and number of repetitions in $\mathrm{NaHCO}_{3}$ condition $(r=-0.005 ; p=0.988)$ and placebo condition $(r=-0.001 ; p=0.997)$.

Figure 2 shows that the two-way ANOVA with repeated measures found a difference of lactate for the effect of time $[\mathrm{F}(1,16)$ $=186 ; p<0.001]$ in $\mathrm{NaHCO}_{3}$ condition $(p<0.001)$ and placebo condition $(p<0.001)$.

\section{Rating of Perceived Exertion and Gastrointestinal side effects}

The Wilcoxon's test did not indicate any differences between $\mathrm{NaHCO} 3$ and placebo conditions for RPE-av, RPE-post5, and GSE. Also, the $f 2$ Cohen's ES was small for all perceptual responses, except for GSE where $f 2$ Cohen's ES was considered moderate when comparing the conditions (Table 2).

\section{Heart rate and rating of perceived exertion in course of time}

Mauchly's test found a violation of sphericity for HR in course of time $(p<0.001)$ and condition $\times$ time $(p<$ $0.001)$. No significant interaction HR was found during the workout in relation to time $\times$ condition $\left[\mathrm{F}_{\text {Greenhouse-Geisser }}\right.$ $(3.4,28)=0.81 ; p=0.518]$. There were no differences $(p$ $>0.01)$ in the times when the $\mathrm{NaHCO}_{3}$ condition was compared with the placebo condition (Figure 3A). However, the two-way ANOVA with repeated measures indicated a difference of $\left[\mathrm{F}_{\text {Greenhouse-Geisser }}(2.1,17)=113 ; p<0.01\right]$ for the effect of time. HR measured at 2 and 4 minutes which was significantly lower $(p<0.007)$ than at 14 minutes. However, between 4 and 12 minutes, HR remained stable with no differences $(p>0.01)$. In the placebo condition, HR at 2 minutes was significantly lower $(p<0.006)$ when compared to measurements made after 16 minutes. It was also significantly lower between 4 and 10 minutes $(p<$ 0.009 ) than at 20 minutes.

Friedman's test indicated that there were no differences $(p>0.05)$ in the times when comparing the $\mathrm{NaHCO}_{3}$ condition with the placebo condition (Figure 3B). However, the RPE showed a difference in the effect of time $(p<$ $0.001)$. In both conditions, the RPE measured between 2 and 6 minutes was significantly lower $(p<0.009)$ when compared to the times after 14 minutes.

The paired t-test and Wilcoxon's test indicated differences between $\mathrm{NaHCO}_{3}$ and placebo conditions for HR-AUC $(p=0.008 ; \mathrm{ES}=0.303)$ and RPE-AUC $(p=0.003 ; \mathrm{ES}=$ $0.256)$, respectively.

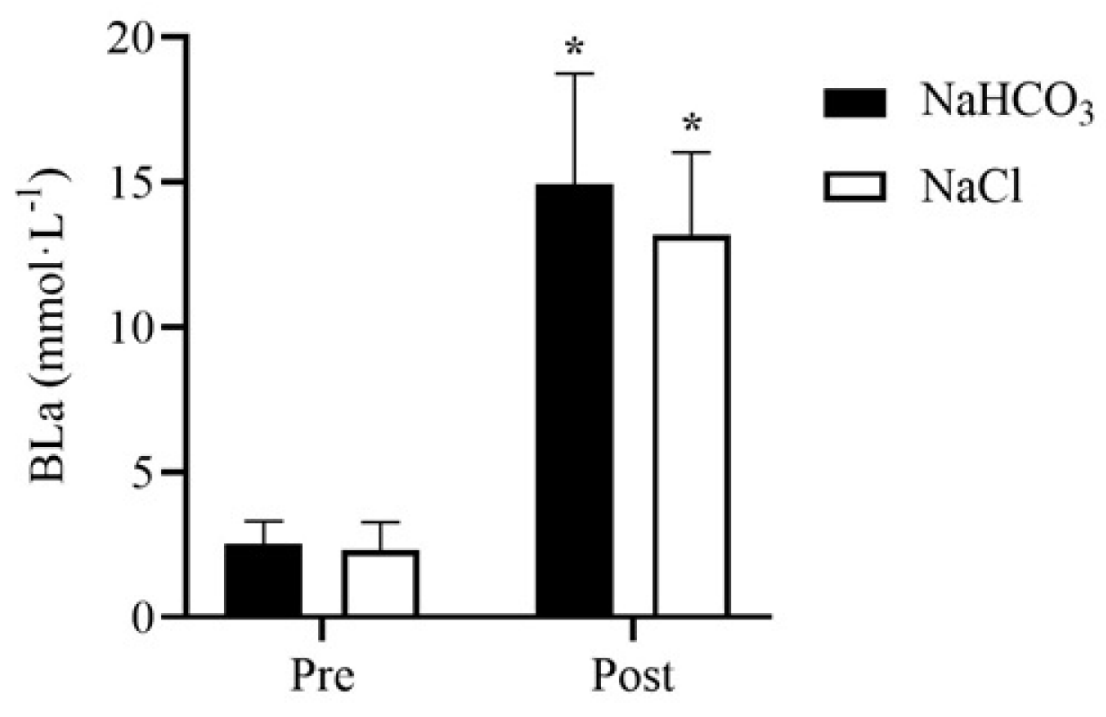

Figure 2 - Blood Lactate for the sodium bicarbonate and placebo conditions.

Values are expressed as mean \pm standard deviation; BLa: Blood lactate; NaHCO3 - sodium bicarbonate; $\mathrm{NaCl}$ - sodium chloride; * Significantly difference compared with pre $(p<0.001)$. 

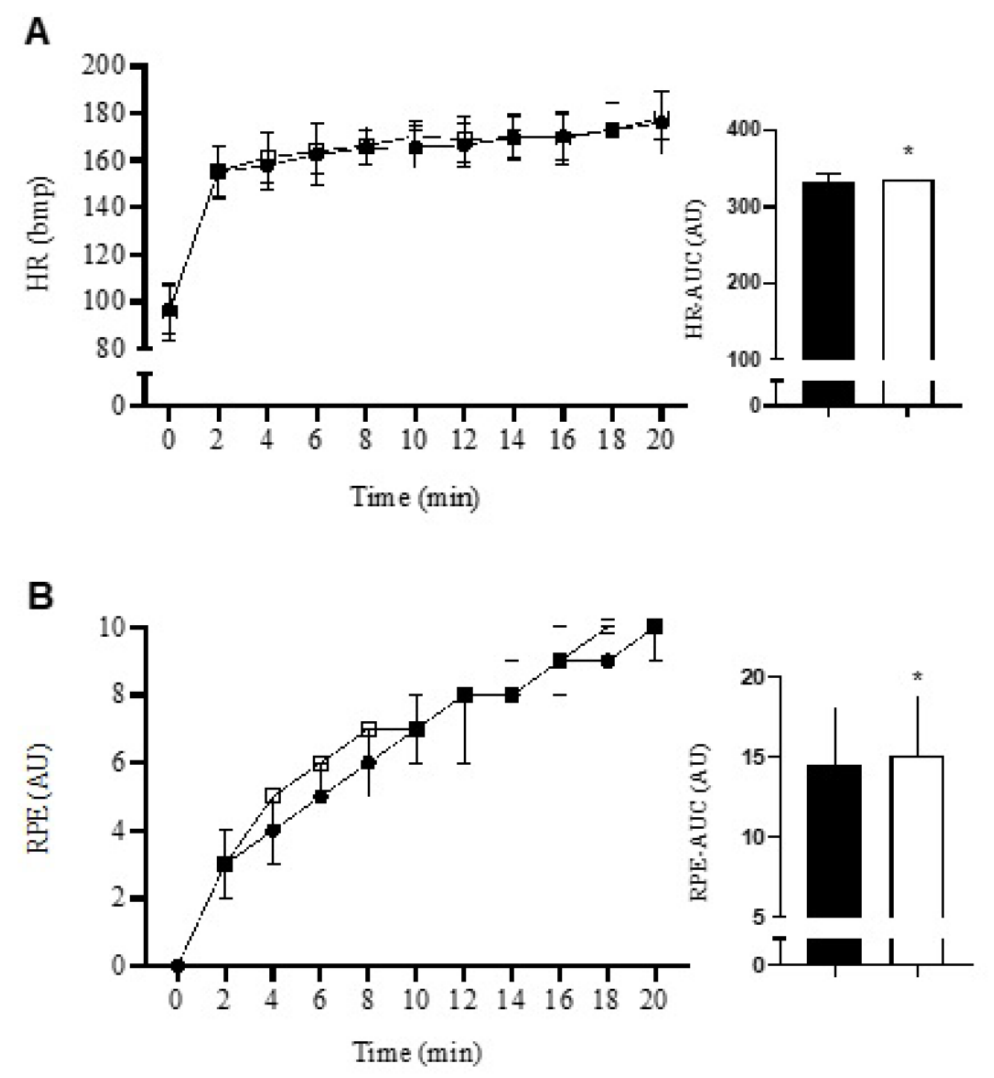

Figure 3 - Heart rate (A) and rating of perceived exertion (B) during the training protocol in both conditions.

- NaHCO3 - sodium bicarbonate; $\square \mathrm{NaCl}$ - sodium chloride; (A) Values are expressed as mean \pm standard deviation; (B) Values are expressed as median (lower-upper $95 \% \mathrm{CI}$ of median); HR - heart rate; RPE - the rating of perceived exertion; bpm - beat per minute; AU - arbitrary units; * Significantly difference compared with $\mathrm{NaHCO} 3$ condition $(p<0.001)$.

Table 1 - Performance results, HR, and Blood Lactate for the sodium bicarbonate and placebo conditions.

\begin{tabular}{lcccc}
\hline & \multicolumn{1}{c}{$\mathbf{N a H C O}_{3}$} & NaCl & p-value & ES \\
\hline Performance (reps) & $491.1 \pm 119.2(399-583)$ & $488.8 \pm 125.7(392-585)$ & 0.67 & 0.02 \\
HR-av (bpm) & $166.1 \pm 9.5(159-173)$ & $167.6 \pm 8.4(161-174)$ & 0.15 & 0.17 \\
HR-peak (bpm) & $177 \pm 11(168-186)$ & $179 \pm 8.9(172-185)$ & 0.50 & 0.21 \\
HR-av (\%) & $87.7 \pm 4(85-91)$ & $88.5 \pm 3.5(86-91)$ & 0.33 & 0.22 \\
HR-peak (\%) & $93.5 \pm 5.1(90-98)$ & $94.3 \pm 4.1(91-98)$ & 0.49 & 0.19 \\
Lactate-pre (mmol·L $\left.{ }^{-1}\right)$ & $2.5 \pm 0.8(1.8-2.9)$ & $2.3 \pm 1(1.6-2.9)$ & 0.75 & 0.23 \\
Lactate-post $\left(\mathrm{mmol} \cdot \mathrm{L}^{-1}\right)$ & $14.9 \pm 3.8(11-17)$ & $13.2 \pm 2.9(10-15.2)$ & 0.22 & 0.53 \\
\hline
\end{tabular}

Values are expressed as mean \pm standard deviation (lower-upper 95\% CI of the mean); $\mathrm{NaHCO}_{3}$ - sodium bicarbonate; $\mathrm{NaCl}$ - sodium chloride; $\mathrm{ES}$ - effect size; HR-av - heart rate average; HR-peak - heart rate peak; pre - before the training protocol; post - after the training protocol; reps - repetitions; bpm - beat per minute; \% - percentage of maximum heart rate; $\mathrm{mmol} \cdot \mathrm{L}^{-1}-$ millimol per liter.

Table 2 - Perceptual responses for the sodium bicarbonate and placebo conditions.

\begin{tabular}{lcccc}
\hline & $\mathbf{N a H C O}_{3}$ & NaCl & p-value & ES \\
\hline RPE-av (AU) & $6.80(4.20-8.30)$ & $7.40(4.60-8.70)$ & 0.15 & 0.45 \\
RPE-post5 (AU) & $5.00(3.70-6.30)$ & $5.00(4.10-6.80)$ & 0.27 & 0.24 \\
GSE (AU) & $6.00(2.20-16.00)$ & $3.00(0.16-8.50)$ & 0.22 & 0.69 \\
\hline
\end{tabular}

Values are expressed as median (lower-upper $95 \% \mathrm{CI}$ of median). $\mathrm{NaHCO}_{3}$ - sodium bicarbonate; $\mathrm{NaCl}$ - sodium chloride; $\mathrm{RPE}$-av - the rating of perceived exertion average; RPE-post5 - the rating of perceived exertion 5 minutes after the training protocol; GSE - gastrointestinal side effects; AU - arbitrary units. 


\section{Discussion}

The present study aimed to verify the acute effect of $\mathrm{NaHCO}_{3}$ supplementation on the performance during CrossFit ${ }^{\circledR}$ workout. We have not confirmed the hypothesis that $\mathrm{NaHCO}_{3}$ supplementation could increase performance during 'Cindy' Cross $F i t{ }^{\circledR}$ workout. The primary results showed that there was not a difference between the $\mathrm{NaHCO}_{3}$ supplementation and placebo conditions related to the number of repetitions of HRav, HR-peak, lactate, RPE-av, RPE-post5, and GSE. However, when the AUC was analyzed, HR and RPE were lower in the $\mathrm{NaHCO}_{3}$ condition. As the AUC represented the total exposure of the workout for HR and RPE, we can consider that over time, $\mathrm{NaHCO}_{3}$ supplementation showed lower cardiovascular work and less perceived effort at the end of the workout.

Blood lactate values increased significantly after the workout in both conditions. Both HR and RPE also showed some significant changes, during the workout regarding the effects of time. Although, a more favorable blood acid-base profile induced by $\mathrm{NaHCO} 3$ supplementation could positively contribute to delay the negative effects of acidosis on contractile and metabolic mechanisms, thus improving performance. This hypothesis was not confirmed by the present study.

Despite the alkalotic state, supposedly, induced in the bloodstream by $\mathrm{NaHCO}_{3}$ supplementation, our results did not show the efficacy of the supplementation in relation to performance. One of the explanations may be related to the oxidative system, since its contribution promotes the removal of $\mathrm{H}^{+}$ions, thus reducing the concentration gradient between the intracellular and extracellular medium ${ }^{28}$. The 'Cindy' workout is based on anaerobic stimuli, but rest between concentric muscle failure and exercises is heavily influenced by aerobic pathways. Results of Feito et al. ${ }^{29}$ suggest that oxygen uptake during the recovery period and total work completed during the trials were the best indicators, which can compromise the effectiveness of $\mathrm{NaHCO}_{3}$ supplementation in the performance of the present study. Supporting, Northgraves et al. ${ }^{30}$ showed that $\mathrm{NaHCO}_{3}$ supplementation did not improve $40-\mathrm{km}$ cycling time trial performance with characteristics of aerobic metabolism.

Previous results ${ }^{12,13,31}$ support that the ergogenic potential of $\mathrm{NaHCO}_{3}$ supplementation depends on the predominant energy pathway in the activity. In CrossFit ${ }^{\circledR}$ training, DurkalecMichalski et al. ${ }^{14}$ found an improvement in overall performance in the 'Fight Gone Bad' workout corresponding to $6 \%$ after $\mathrm{NaHCO}_{3}$ supplementation. The total duration of 'Fight Gone Bad' is similar to 'Cindy' (17 and 20 minutes, respectively). This performance improvement might be explained by the use of supplementation in progressive doses, as the supplementation model differs from the model used in the present study or even by the characteristics of specific movements of each workout: movement with external load in 'Fight Gone Bad' and gymnastic movements in 'Cindy'.

Although 'Cindy' is a long workout at a lesser pace, in the present study, blood lactate values have increased substantially in both conditions. However, higher blood lactate values were expected in the $\mathrm{NaHCO}_{3}$ condition when compared with placebo, since the lactate efflux from muscle cells into the bloodstream is increased after $\mathrm{NaHCO}_{3}$ supplementation ${ }^{32}$. The $\mathrm{HCO}_{3}^{-}$levels are related to the activation of the monocarboxylate transporter, which transports the $\mathrm{H}^{+}$ions and lactate from the sarcolemma to the bloodstream ${ }^{33}$. However, trained individuals have better acidosis tolerance conditions than physically active or untrained individuals, which may be due to the fact that acute and chronic exercise increase monocarboxylate transporter activity ${ }^{34}$. This would explain the lack of the ergogenic effect of $\mathrm{NaHCO}_{3}$ supplementation in the present study. As our results, CorreiaOliveira et al. ${ }^{35}$ found no differences in blood lactate values after a cycling time trial with a distance of $4 \mathrm{~km}$ and a duration of approximately six to seven minutes. In contrast, Ferreira et al. ${ }^{1}$ showed that a higher dose of $\mathrm{NaHCO}_{3}$ supplementation $(0.3$ g. $\mathrm{kg}^{-1}$ of bodyweight of $\mathrm{NaHCO}_{3}$ ) promoted high lactate levels after a test lasting approximately 70 seconds when compared to a lower dose of $\mathrm{NaHCO}_{3}$ supplementation $\left(0.1 \mathrm{~g} \cdot \mathrm{kg}^{-1}\right.$ of the body weight of $\mathrm{NaHCO}_{3}$ ) and placebo.

HR differences during the workout seem to be related to the cadence of movement. A CrossFit ${ }^{\circledR}$ training program does not have a standard cadence. Each athlete, in a self-selected way, controls the intensity of the effort for better performance ${ }^{36}$. As well as the present study, Durkalec-Michalski et al. ${ }^{14}$ did not show differences in the HR-av and HR-peak in an incremental cycling test. An interesting fact in the aforementioned study is that the HR values at the ventilatory threshold were similar to the HR-av values in the present study for CrossFit ${ }^{\circledR}$ training recreational practitioners, regardless of the condition. To check the behavior of HR over time, the AUC was evaluated, and that HR was lower in $\mathrm{NaHCO}_{3}$ supplementation. This result has not yet been widely discussed in the literature, as previous studies with $\mathrm{NaHCO}_{3}$ supplementation did not perform the analysis of $\mathrm{AUC}^{12,14}$.

RPE-av and RPE-post5 were not influenced by $\mathrm{NaHCO}_{3}$ supplementation. Over time, the feeling of fatigue increases, regardless of whether the exercise is continuous or intermittent $^{37}$. The results of the present study corroborate those of other studies ${ }^{38,39}$, which did not observe differences in the RPE-av and RPE-post5. However, similarly, HR-AUC, RPEAUC were lower in $\mathrm{NaHCO}_{3}$ supplementation, in which the feeling of fatigue depended on metabolic, circulatory, and psychochemical aspects ${ }^{40}$, which are summarized in the course of workout time. It is conceivable that a threshold change in $\mathrm{pH}$ or $\mathrm{HCO}_{3}{ }^{-}$is necessary to trigger an alteration in the peripheral sensation of exertion ${ }^{41}$.

The use of $\mathrm{NaHCO}_{3}$ supplementation, depending on the dosage (i.e., doses above $0.3 \mathrm{~g} . \mathrm{kg}^{-1}$ of the body weight of $\mathrm{NaHCO}_{3}$ ), may not be recommended, as there is an increase in the incidence of adverse effects, such as $\mathrm{GSE}^{42}$. A possible strategy, as previously reported, is to split the intake of supplementation into equal doses ${ }^{21}$. A higher incidence and severity of gastrointestinal symptoms after $\mathrm{NaHCO}_{3}$ supplementation can negatively affect physical performance ${ }^{16}$. However, despite the lack of significance for GSE, the moderate effect size (ES $=0.69$ ) incorporates the idea that GSE may have influenced performance, even if minimally, and is perhaps responsible for the lack of ergogenic effect of $\mathrm{NaHCO}_{3}$ supplementation. Thus, alternatives such as testing supplementation during 
training before using it in competitive situations and the use of progressive doses of supplementation becomes relevant to the athlete's good performance ${ }^{14}$.

Although this study provides practical and scientific evidence on the use of $\mathrm{NaHCO}_{3}$ supplementation in practitioners trained in CrossFit $\AA$ training, there are some limitations in this paper. Perhaps it would be more interesting if more blood collections were taken after the workout to analyze the lactate kinetics. Despite the sample calculation carried out a priori, perhaps the use of a small ES, which would represent more participants, could improve analysis regarding the benefit of supplementation on performance. As CrossFit ${ }^{\circledR}$ training is a program that involves several characteristics and elements, the analysis of the responses of sodium bicarbonate use in other workouts is necessary for better discussions about the results.

\section{Conclusion}

Acute $\mathrm{NaHCO}_{3}$ supplementation did not improve performance in the 'Cindy' CrossFit ${ }^{\circledR}$ workout in experienced men. Hemodynamic and perceptual parameters were influenced by supplementation during a workout over the course of time and $\mathrm{NaHCO}_{3}$ supplementation did not promote GSE.

\section{References}

1. Ferreira LHB, Smolarek AC, Chilibeck PD, Barros MP, McAnulty SR, Schoenfeld BJ, et al. High doses of sodium bicarbonate increase lactate levels and delay exhaustion in a cycling performance test. Nutrition. 2019;60:94-9.

2. Siegler JC, Marshall PWM, Finn H, Cross R, Mudie K. Acute attenuation of fatigue after sodium bicarbonate supplementation does not manifest into greater training adaptations after 10-weeks of the resistance training exercise. PLoS One. 2018;13(5):e0196677.

3. Lancha Junior AH, Painelli Vde S, Saunders B, Artioli GG. Nutritional Strategies to Modulate Intracellular and Extracellular Buffering Capacity During High-Intensity Exercise. Sports Med. 2015;45 Suppl 1:S71-81.

4. Del Coso J, Hamouti N, Aguado-Jimenez R, Mora-Rodriguez R. Restoration of blood $\mathrm{pH}$ between repeated bouts of high-intensity exercise: effects of various active-recovery protocols. Eur J Appl Physiol. 2010;108(3):523-32.

5. Siegler JC, Marshall PW, Bishop D, Shaw G, Green S. Mechanistic Insights into the Efficacy of Sodium Bicarbonate Supplementation to Improve Athletic Performance. Sports Med Open. 2016;2(1):41.

6. Spriet LL, Lindinger MI, McKelvie RS, Heigenhauser GJ, Jones NL. Muscle glycogenolysis and $\mathrm{H}+$ concentration during maximal intermittent cycling. J Appl Physiol 1989;66(1):8-13.

7. Chin ER, Allen DG. The contribution of $\mathrm{pH}$-dependent mechanisms to fatigue at different intensities in mammalian single muscle fibers. J Physiol. 1998;512 ( Pt 3)(Pt 3):831-40.

8. Westerblad H, Allen DG. The influence of intracellular $\mathrm{pH}$ on contraction, relaxation, and $[\mathrm{Ca} 2+] \mathrm{i}$ in intact single fibers from mouse muscle. J Physiol. 1993;466:611-28.
9. Fabiato A, Fabiato F. Effects of $\mathrm{pH}$ on the myofilaments and the sarcoplasmic reticulum of skinned cells from cardiac and skeletal muscles. J Physiol. 1978;276:233-55.

10. Street D, Nielsen JJ, Bangsbo J, Juel C. Metabolic alkalosis reduces exercise-induced acidosis and potassium accumulation in human skeletal muscle interstitium. J Physiol. 2005;566(Pt 2):481-9.

11. Artioli GG, Gualano B, Smith A, Stout J, Lancha AH, Jr. Role of beta-alanine supplementation on muscle carnosine and exercise performance. Med Sci Sports Exerc. 2010;42(6):1162-73.

12. Siegler JC, Hirscher K. Sodium bicarbonate ingestion and boxing performance. J Strength Cond Res. 2010;24(1):103-8.

13. Lopes-Silva JP, Da Silva Santos JF, Artioli GG, Loturco I, Abbiss C, Franchini E. Sodium bicarbonate ingestion increases glycolytic contribution and improves performance during simulated taekwondo combat. Eur J Sports Sci. 2018;18(3):431-40.

14. Durkalec-Michalski K, Zawieja EE, Podgórski T, Łoniewski I, Zawieja BE, Warzybok M, et al. The effect of chronic progressive-dose sodium bicarbonate ingestion on CrossFit-like performance: A double-blind, randomized cross-over trial. PLoS One. 2018;13(5):e0197480.

15. Driller MW, Gregory JR, Williams AD, Fell JW. The effects of chronic sodium bicarbonate ingestion and interval training in highly trained rowers. Int J Sport Nutr Exerc Metab. 2013;23(1):40-7.

16. Cameron SL, McLay-Cooke RT, Brown RC, Gray AR, Fairbairn KA. Increased blood $\mathrm{pH}$ but not performance with sodium bicarbonate supplementation in elite rugby union players. Int J Sport Nutr Exerc Metab. 2010;20(4):307-21.

17. Glassman G. Understanding CrossFit. CrossFit Journal. 2007;56:2

18. Faul F, Erdfelder E, Lang AG, Buchner A. G*Power 3: a flexible statistical power analysis program for the social, behavioral, and biomedical sciences. Behav Res Methods. 2007;39(2):175-91.

19. Beck TW. The importance of a priori sample size estimation in strength and conditioning research. J Strength Cond Res. 2013;27(8):2323-37.

20. Duffield R, Dawson B, Goodman C. Energy system contribution to $100-\mathrm{m}$ and $200-\mathrm{m}$ track running events. J Sci Med Sport. 2004;7(3):302-13.

21. Bishop D, Claudius B. Effects of induced metabolic alkalosis on prolonged intermittent-sprint performance. Med Sci Sports Exerc. 2005;37(5):759-67.

22. Jones RL, Stellingwerff T, Artioli GG, Saunders B, Cooper $\mathrm{S}$, Sale C. Dose-Response of Sodium Bicarbonate Ingestion Highlights Individuality in Time Course of Blood Analyte Responses. Int J Sport Nutr Exerc Metab. 2016;26(5):445-53.

23. Robertson RJ, Goss FL, Rutkowski J, Lenz B, Dixon C, Timmer J, et al. Concurrent validation of the OMNI perceived exertion scale for resistance exercise. Med Sci Sports Exerc. 2003;35(2):333-41.

24. Bishop D. Evaluation of the Accusport lactate analyzer. Int J Sports Med. 2001;22(7):525-30.

25. Jeukendrup AE, Vet-Joop K, Sturk A, Stegen JH, Senden J, Saris WH, et al. Relationship between gastro-intestinal complaints and endotoxaemia, cytokine release and the acute-phase 
reaction during and after a long-distance triathlon in highly trained men. Clin Sci. 2000;98(1):47-55.

26. Dworkin RH, Turk DC, Farrar JT, Haythornthwaite JA, Jensen MP, Katz NP, et al. Core outcome measures for chronic pain clinical trials: IMMPACT recommendations. Pain. 2005;113(1-2):9-19.

27. Hopkins WG, Marshall SW, Batterham AM, Hanin J. Progressive statistics for studies in sports medicine and exercise science. Med Sci Sports Exerc. 2009;41(1):3-13.

28. Matson LG, Tran ZV. Effects of sodium bicarbonate ingestion on anaerobic performance: a meta-analytic review. Int J Sport Nutr. 1993;3(1):2-28.

29. Feito Y, Giardina MJ, Butcher S, Mangine GT. Repeated anaerobic tests predict performance among a group of advanced CrossFit-trained athletes. Appl Physiol Nutr Metab. 2019;44(7):727-35.

30. Northgraves MJ, Peart DJ, Jordan CA, Vince RV. Effect of lactate supplementation and sodium bicarbonate on 40-km cycling time trial performance. J Strength Cond Res. 2014;28(1):273-80.

31. Farney TM, MacLellan MJ, Hearon CM, Johannsen NM, Nelson AG. The Effect of Aspartate and Sodium Bicarbonate Supplementation on Muscle Contractile Properties Among Trained Men. J Strength Cond Res. 2020;34(3):763-70.

32. Roth DA. The sarcolemmal lactate transporter: transmembrane determinants of lactate flux. Med Sci Sports Exerc. 1991;23(8):925-34.

33. Brooks GA, Dubouchaud H, Brown M, Sicurello JP, Butz CE. Role of mitochondrial lactate dehydrogenase and lactate oxidation in the intracellular lactate shuttle. Proc Natl Acad Sci U S A. 1999;96(3):1129-34.

34. Thomas C, Bishop DJ, Lambert K, Mercier J, Brooks GA. Effects of acute and chronic exercise on sarcolemmal MCT1 and MCT4 contents in human skeletal muscles: current status. Am J Physiol Regul Integr Comp Physiol. 2012;302(1): R1-14.

35. Correia-Oliveira CR, Lopes-Silva JP, Bertuzzi R, McConnell GK, Bishop DJ, Lima-Silva AE, et al. Acidosis, but Not Alkalosis, Affects Anaerobic Metabolism and Performance in a 4-km Time Trial. Med Sci Sports Exerc. 2017;49(9):1899-910.

36. Butcher SJ, Neyedly TJ, Horvey KJ, Benko CR. Do physiological measures predict selected CrossFit(R) benchmark performance? J Sports Med. 2015;6:241-7.

37. Christensen PM, Petersen MH, Friis SN, Bangsbo J. Caffeine, but not bicarbonate, improves 6 min maximal performance in elite rowers. Appl Physiol Nutr Metab. 2014;39(9):1058-63.
38. Artioli GG, Gualano B, Coelho DF, Benatti FB, Gailey AW, Lancha AH, Jr. Does sodium-bicarbonate ingestion improve simulated judo performance? Int J Sport Nutr Exerc Metab. 2007;17(2):206-17.

39. Stephens TJ, McKenna MJ, Canny BJ, Snow RJ, McConnell GK. Effect of sodium bicarbonate on muscle metabolism during intense endurance cycling. Med Sci Sports Exerc. 2002;34(4):614-21.

40. Noble BJ, Robertson RJ. Perceived Exertion. Champaign, IL: Human Kinetics, 1996.

41. Swank A, Robertson RJ. Effect of induced alkalosis on the perception of exertion during intermittent exercise. J Appl Physiol (1985). 1989;67(5):1862-7.

42. McNaughton LR. Bicarbonate ingestion: effects of dosage on 60 s cycle ergometry. J Sports Sci. 1992;10(5):415-23.

\section{Acknowledgments}

The authors would like to thank CrossFit Juiz de Fora for its support in the present study and each of the participants for their efforts.

\section{Corresponding author}

Marcelo Ricardo Dias.

Faculdade Metodista Granbery, Laboratório de Fisiologia do Exercício e Avaliação Morfofuncional. R. Batista de Oliveira, 1.145 - Granbery, Juiz de Fora - MG, 36010-530. Juiz de Fora,MG. Brasil. Telephone: +55 (32) 99194-0154 Email: diasmr@gmail.com

Manuscript received on April 20, 2020

Manuscript accepted on August 24, 2020

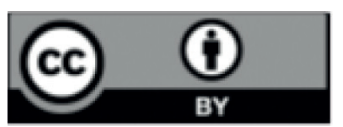

Motriz. The Journal of Physical Education. UNESP. Rio Claro, SP, Brazil - eISSN: 1980-6574 - under a license Creative Commons - Version 4.0 